\title{
Research on the Field Dynamic Balance Technologies for Large Diesel Engine Crankshaft System
}

\author{
Shihai Zhang and Zimiao Zhang \\ College of Mechanical Engineering, Tianjin University of Technology and Education, Tianjin 300222, China \\ Correspondence should be addressed to Shihai Zhang; zshky77@163.com
}

Received 15 June 2017; Revised 29 August 2017; Accepted 18 September 2017; Published 18 October 2017

Academic Editor: Mahmoud Bayat

Copyright (c) 2017 Shihai Zhang and Zimiao Zhang. This is an open access article distributed under the Creative Commons Attribution License, which permits unrestricted use, distribution, and reproduction in any medium, provided the original work is properly cited.

\begin{abstract}
In order to reduce the unbalancing mass and the accompanying unbalancing vibration of diesel engine crankshaft system, the field dynamic balancing method and its key technologies are presented in the paper. In order to separate the unbalancing vibration signal from the total vibration signal of crankshaft system, the fundamental frequency signal fitting principle based on the least square method was introduced firstly, and then wavelet noise reduction method was applied to improve the signal fitting precision of least square method. Based on the unbalancing vibration signal analysis and assessment of crankshaft system, the influence coefficient method was applied to calculate the value and phase of the equivalent unbalancing mass in flywheel. To easily correct the unbalancing condition of crankshaft system, the unbalancing adjustment equipment was designed based on the flywheel structure. The balancing effect of field dynamic balancing system designed for the large diesel engine has been verified by field experiments.
\end{abstract}

\section{Introduction}

The large diesel engine is the important generating and power equipment of ships. In practice, the unbalancing mass of crankshaft system may be generated and beyond the allowable range affected by the factors of machining precision, installation precision, wear and deformation, and so forth. The huge unbalancing vibration of crankshaft system may be aroused by the unbalance mass of crankshaft system, which can destroy the running stability of diesel engine and then deteriorate the wear condition among the movement units. So the suitable balancing method should be applied to reduce the unbalancing mass and unbalancing vibration of crankshaft system.

The balancing object of diesel engine crankshaft system includes the reciprocating inertia force and rotation inertia force. In general, the special balancing mechanism is installed in diesel engine to balance the reciprocating inertia force. In 1911, the double-shaft balance technology was invented by Lanchester [1]. In 2002, a world class balance shaft system for the 2AZ-FE engine was achieved by Ishikawa et al. using resin gears for the first time ever. Reliability was achieved by developing the high-strength resin optimal impact absorption characteristics [2]. In 2007, the new concept of "thick-thin double-shaft" balancing method for 4-cylinder diesel engine was proposed by Fan et al. [3]. In 2009, Solferino proposed an internal combustion engine with a crankshaft and first and second balance shafts, which were gear driven from one to the other, as a unilateral tensioning system applied to a flexible drive extending between the engine's crankshaft and the first one of the balance shafts [4]. In 2015, Sajdowitz et al. described a balance system for a single-cylinder engine, for which the balance shaft included a primary balance shaft for the first type of forces and at least one secondary balance shaft for the second type of forces [5].

The counterweights are usually used to balance the rotation inertia force, and the layout methods of counterweights include sectioning balancing method, integral balancing method, and irregular balancing method. In 2000, the mass center displacement method was applied to study the balancing performance of internal combustion engine by Sun and Fang [6]. In 2007, the slipper type balancing mechanism was applied to study and analyze the balancing performance of single-cylinder diesel engine by Sun et al. [7]. In 2009, the effects of counterweight mass and position 
on main bearing load and crankshaft bending stress of an in-line six-cylinder diesel engine were investigated using multibody system simulation program, ADAMS, by Yilmaz and Anlas [8]. In 2009, the model consisting of crankshaft, connecting rod, and piston was introduced by Yang et al. to separate the reciprocating mass and rotating mass of connecting rod assembly based on the multibody dynamics simulation [9]. In 2011, Liu and Huston presented a set of formulae for determining the ring weights needed for balancing crankshafts of six-cylinder V60 degree engines [10]. In 2012, an optimal conceptual design of a balance shaft was presented by Kim et al. through determining locations of both unbalance and supporting bearing [11]. In 2012, Karabulut devised a three-degree-of-freedom dynamic model for a twocylinder four-stroke engine, which enabled the simultaneous treatment of the piston-crankshaft mechanism and engine block. A simple relation had been obtained to determine the position and mass of counterweights used for eliminating the vertical vibration of the block [12]. In 2015, Huo et al. built a counterweight theoretical model of transmission mechanism to obtain the values of counterweight and counter-balanced phase angle on crankshaft and output shaft [13]. In 2016, Ipci and Karabulut conducted the conjugate thermodynamic and dynamic modeling of a single-cylinder four-stroke diesel engine, of which the counterweight mass and its radial distance were optimized [14]. In order to study the balance of offset crankshaft engine, a new equation was derived from the traditional one for the kinematics analysis of pistoncrank system by Tang et al. in 2016, which was performed on a 3-cylinder engine with single crankshaft and excessive counterweight to calculate the phase relationship between the balance shaft and the counterweight [15].

In practice, the unbalancing condition of crankshaft system may be changed when the diesel engine runs for a long time. In order to adapt the unbalancing condition variation of crankshaft system, the field balancing was proposed by Keizai Seminar et al. in the 1990s. Based on the field balancing method, the unbalance of crankshaft system could be measured and corrected in field, and the balancing precision and its timeliness could be ensured $[16,17]$.

\section{The Separating Method of Unbalancing Vibration Signal}

In practice, a lot of harmonic and noise signals are included in the vibration signal of crankshaft system. Different harmonic signals represent different exciting factors, and the unbalancing vibration signal belongs to the fundamental frequency component confused in the total vibration signal of crankshaft system. In order to analyze the unbalancing condition of crankshaft system, the unbalancing vibration signal should be separated from the total vibration signal firstly. The traditional methods concentrated on the filtering and noise reduction based on the Fourier transform. It has been found that the fundamental frequency components of other signals may be confused in the separated fundamental frequency signal based on the traditional methods, and these fundamental frequency components cannot be corrected by the dynamic balancing method [18]. In order to reduce the fundamental frequency components interference of other signals, the least square method was applied to fit the fundamental frequency signal of unbalancing vibration [18].

According to the Fourier series principle, we express the vibration signal of the crankshaft system as the following:

$$
y=b+\sum_{i=1}^{n} Y_{i} \sin \left(2 i \pi f_{1} t+\varphi_{i}\right)
$$

In (1), $y$ represents the vibration signal, $b$ represents the constant term of the vibration signal, the amplitude and phase of the $i$ th order frequency component are, respectively, expressed as $Y_{i}$ and $\varphi_{i}(i=1,2, \ldots, n), f_{1}$ represents the frequency of the fundamental frequency signal. According to the trigonometric function calculation, we get

$$
\begin{aligned}
y= & b+\sum_{i=1}^{n} Y_{i} \cos \varphi_{i} \sin \left(2 i \pi f_{1} t\right) \\
& +\sum_{i=1}^{n} Y_{i} \sin \varphi_{i} \cos \left(2 i \pi f_{1} t\right) .
\end{aligned}
$$

We linearize (2) as

$$
y=b+\sum_{i=1}^{2 n} a_{i} x_{i}
$$

The relationship of the parameters in (2) and (3) can be acquired in (4) and (5).

$$
\begin{gathered}
a_{i}= \begin{cases}Y_{i} \cos \varphi_{i}, & i=1,3, \ldots, 2 n-1 \\
Y_{i} \sin \varphi_{i}, & i=2,4, \ldots, 2 n\end{cases} \\
x_{i}= \begin{cases}\sin \left(2 i \pi f_{1} t\right), & i=1,3, \ldots, 2 n-1 \\
\cos \left(2 i \pi f_{1} t\right), & i=2,4, \ldots, 2 n .\end{cases}
\end{gathered}
$$

We assume $f s$ as the sample frequency and $m$ as the sample length; then we can get the discrete equation of (5) as the following:

$$
x_{i, j}=\left\{\begin{array}{rr}
\sin \left(\frac{2 i \pi f_{1} j}{f_{s}}\right), & i=1,3, \ldots, 2 n-1 \\
\cos \left(\frac{2 i \pi f_{1} j}{f s}\right), & i=2,4, \ldots, 2 n \\
& j=1,2, \ldots, m .
\end{array}\right.
$$

According to the principle of the least square method, we establish the target function as

$$
\phi\left(a_{1}, \ldots, a_{2 n}, b\right)=\sum_{j=1}^{m}\left(y-y_{j}\right)^{2} .
$$

In function (7), $y_{j}$ represents the discrete value of the sample signal. To take, respectively, function (7) partial 


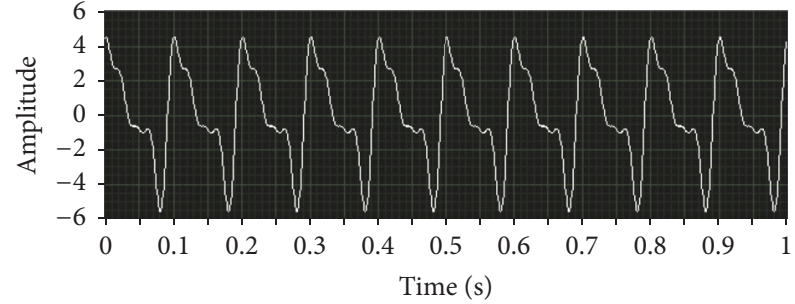

(a) The simulation signal without noise signal

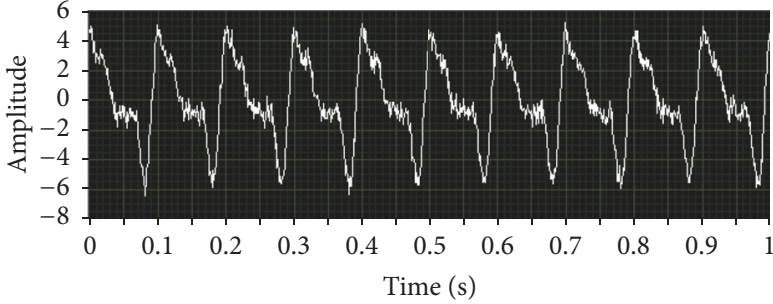

(b) The simulation signal with uniform white noise signal

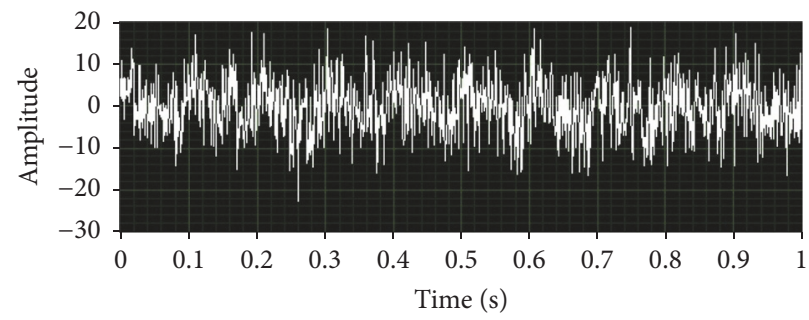

(c) The simulation signal with periodic random noise signal

FIgURE 1: The simulation signal.

derivative with respect to $a_{1}, a_{2}, \ldots, a_{2 n}, b$ which is equal to zero, we get the partial derivative equations as the following:

$$
\begin{aligned}
& \frac{\partial \phi}{\partial a_{1}}=\sum_{j=1}^{m} 2\left(y-y_{i}\right) x_{1, j}=b \sum_{j=1}^{m} x_{1, j} \\
& +\sum_{j=1}^{m} x_{1, j} \sum_{i=1}^{2 n} a_{i} x_{i, j}-\sum_{j=1}^{m} x_{1, j} y_{i}=0 \\
& \vdots \\
& \frac{\partial \phi}{\partial a_{k}}=\sum_{j=1}^{m} 2\left(y-y_{i}\right) x_{k, j} \\
& =b \sum_{j=1}^{m} x_{k, j}+\sum_{j=1}^{m} x_{k, j} \sum_{i=1}^{2 n} a_{i} x_{i, j}-\sum_{j=1}^{m} x_{k, j} y_{i}=0 \\
& \frac{\partial \phi}{\partial a_{2 n}}=\sum_{j=1}^{m} 2\left(y-y_{i}\right) x_{2 n, j} \\
& =b \sum_{j=1}^{m} x_{2 n, j}+\sum_{j=1}^{m} x_{2 n, j} \sum_{i=1}^{2 n} a_{i} x_{i, j}-\sum_{j=1}^{m} x_{2 n, j} y_{i}=0 \\
& =\sum_{j=1}^{m} 2\left(y-y_{i}\right)=\sum_{j=1}^{m} b+\sum_{j=1}^{m} \sum_{i=1}^{2 n} a_{i} x_{i, j}-\sum_{j=1}^{m} y_{i}=0 .
\end{aligned}
$$

Equation $(8)$ is the $(2 n+1) \times(2 n+1)$ order linear normal equations and can be solved through the Gauss PCA elimination method. We can calculate the values of the parameters $a_{1}, a_{2}, \ldots, a_{2 n}, b$ and then gain the values $Y_{i}$ and $\varphi_{i}$ by solving

$$
\begin{aligned}
Y_{i}^{2} & =a_{2 i-1}^{2}+a_{2 i}^{2} \\
\varphi_{i} & =\arctan \left(\frac{a_{2 i}}{a_{2 i-1}}\right) .
\end{aligned}
$$

To test the precision of the method, we design the signal simulation and fitting programs by Labview language. The equation of the simulation signal is expressed as the following:

$$
\begin{aligned}
y= & 3 \sin \left(20 \pi t+\frac{\pi}{6}\right)+2 \sin \left(40 \pi t+\frac{\pi}{4}\right) \\
& +1.2 \sin \left(60 \pi t+\frac{11 \pi}{18}\right)+0.7 \sin \left(80 \pi t+\frac{3 \pi}{4}\right) \\
& +\delta(t) .
\end{aligned}
$$

In $(10), \delta(t)$ is the noise signal. In order to analyze the signal fitting effect, the uniform white noise signal and periodic random noise signal are added, respectively, in simulation signal. The amplitude of noise signals is set as 0.4 for comparison purposes. The simulation signals are shown in Figure 1.

Based on the signals of Figure 1, the least square method is used, respectively, to fit the first 3 order components of the simulation signals. The fitting results are shown in Table 1.

From Table 1 we can see that the least square method can accurately fit the fundamental frequency signal. But the noise signal has small effect on the fitting accuracy; therefore we can adopt the suitable filtering method to reduce the noise interference in the practical application.

Practice shows that the vibration signal of diesel crankshaft system contains a large number of periodic random noise signals and nonstationary signals, while the traditional 
TABLE 1: The amplitudes and phases of the first 3-order frequency component fitted by least square method.

\begin{tabular}{|c|c|c|c|c|c|c|}
\hline \multirow[t]{2}{*}{ Orders } & \multicolumn{2}{|c|}{ Without noise signal } & \multicolumn{2}{|c|}{ The uniform white noise signal is added } & \multicolumn{2}{|c|}{$\begin{array}{l}\text { The periodic random } \\
\text { noise signal is added }\end{array}$} \\
\hline & Amplitude & Phase & Amplitude & Phase & Amplitude & Phase \\
\hline 1 & 3 & $30^{\circ}$ & 2.98 & $29.93^{\circ}$ & 2.66 & $25.61^{\circ}$ \\
\hline 2 & 2 & $45^{\circ}$ & 1.99 & $44.73^{\circ}$ & 2.29 & $37.85^{\circ}$ \\
\hline 3 & 1.2 & $110^{\circ}$ & 1.21 & $110.27^{\circ}$ & 1.38 & $125.84^{\circ}$ \\
\hline
\end{tabular}
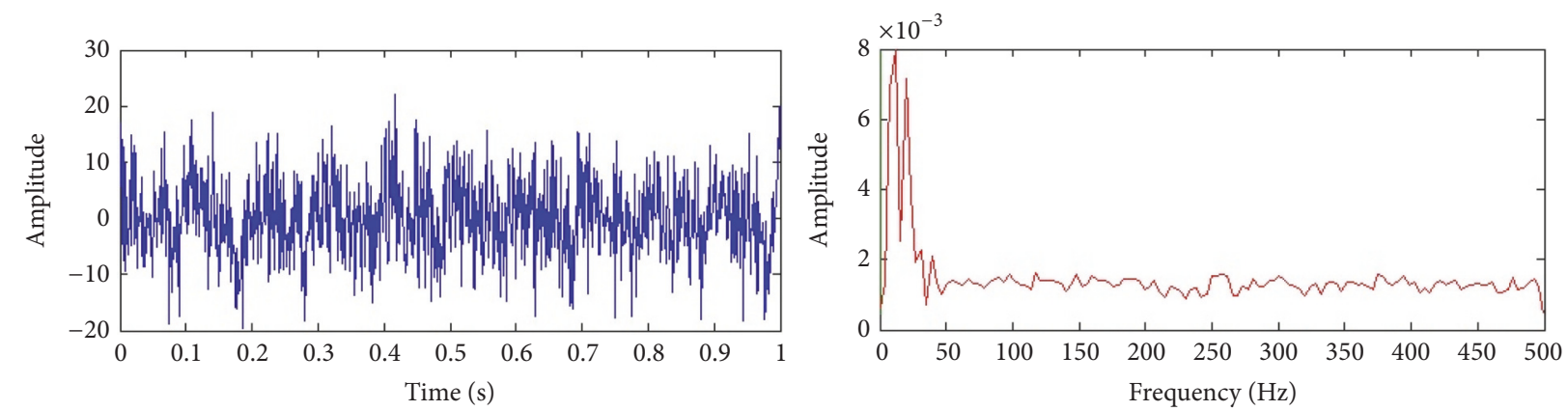

(a) The original signal and its power spectrum
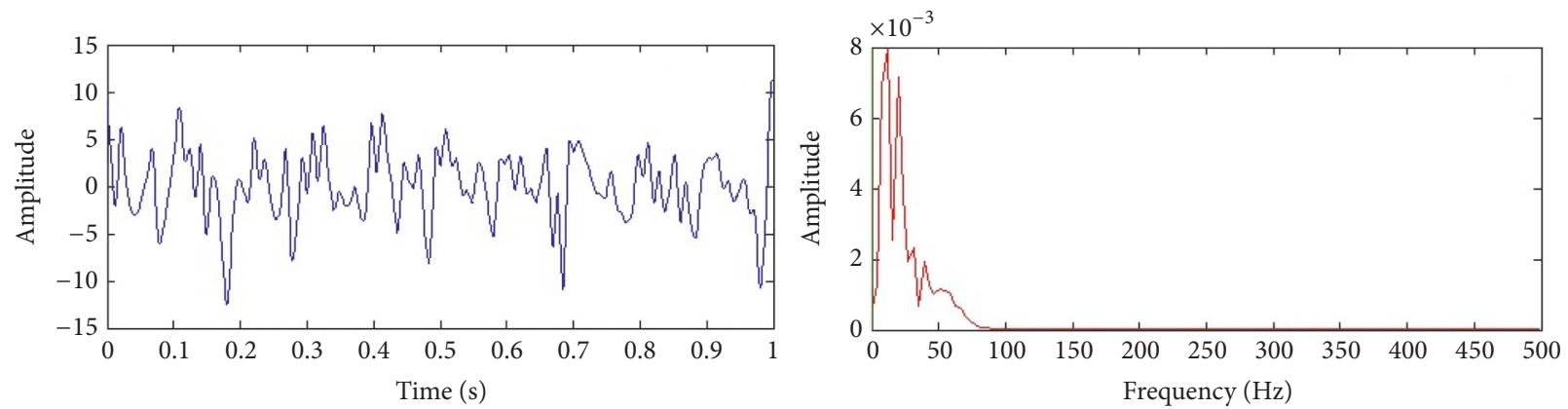

(b) The residual signal and its power spectrum after wavelet noise reduction

FIGURE 2: The filtering effect of wavelet noise reduction method.

Fourier transform method has great difficulties for detecting nonstationary signals.

Studies showed that harmonic wavelet analysis could analyze nonstationary and strong noise signals $[19,20]$. Moreover the harmonic wavelet had phase keeping function for each harmonic component, which was very important to extract the vibration signals of rotor unbalance.

According to the wavelet transform definition, the wavelet transform of a time domain signal $x(t) \in L^{2}(R)$ related to wavelet function $W_{m, n}(t)$ at a certain scale can be expressed as

$$
W(t)=\int_{-\infty}^{\infty} x(\tau) \psi_{m, n}^{*}(t-\tau) d \tau .
$$

The harmonic wavelet transform of signal $x(t)$ can be expressed as

$$
W(m, n, k)=(n-m) \int_{-\infty}^{\infty} x(t) \psi_{m, n}^{*}\left(t-\frac{k}{n-m}\right) d \tau .
$$

Equation (12) was the time domain harmonic wavelet transform at $m$ and $n$ scales. $M$ and $n$ were equivalent to the scaling factors of the harmonic wavelet transform. Transforming equation (12) by the Fourier transformation, we get

$$
W_{x}(m, n, \omega)=\widehat{X}(\omega) \widehat{\psi}_{m, n}^{*}[(n-m) \omega] .
$$

Equation (13) was the frequency domain harmonic wavelet transform at $m$ and $n$ scales. For discrete signal sequences $x(r), r=0,1, \ldots, N-1$, the harmonic wavelet transform was

$$
W(m, n, k)=\frac{n-m}{N} \sum_{r=0}^{N-1} x(r) \widehat{\psi}_{m, n}^{*}\left[r-\frac{k}{n-m}\right] .
$$

It can be seen from (11) to (14) that harmonic wavelet transform is relatively simple and easy to implement. After the signal is decomposed by harmonic wavelet, the local spectrum of different frequency bands is refined and analyzed, respectively, in different decomposition layers and on the same layer. Then the signal is reconstructed to realize the noise reduction. Figure 2 shows the time domain signal and power spectrum before and after signal filtering of Figure 1(c). 
TABLE 2: The signal fitting accuracy of the initial signal and the denoised signal.

\begin{tabular}{|c|c|c|c|c|c|}
\hline & $\begin{array}{c}\text { Theoretical } \\
\text { value }\end{array}$ & $\begin{array}{c}\text { Fitting value of } \\
\text { initial signal }\end{array}$ & $\begin{array}{l}\text { Error } \\
\text { value }\end{array}$ & $\begin{array}{l}\text { Fitting value of } \\
\text { denoised signal }\end{array}$ & $\begin{array}{l}\text { Error } \\
\text { value }\end{array}$ \\
\hline The amplitude of fundamental frequency signal & 3 & 2.6637 & 0.3363 & 3.0449 & 0.0449 \\
\hline The phase of fundamental frequency signal & 30 & 25.6087 & 4.3913 & 28.3062 & 1.6938 \\
\hline The amplitude of second harmonic frequency signal & 2 & 2.2977 & 0.2977 & 1.9665 & 0.0335 \\
\hline The phase of second harmonic frequency signal & 45 & 37.8548 & 7.1452 & 47.7221 & 2.7221 \\
\hline The amplitude of third harmonic frequency signal & 1.2 & 1.3839 & 0.1839 & 1.2967 & 0.0967 \\
\hline The phase of third harmonic frequency signal & 110 & 125.842 & 15.8421 & 108.827 & 1.1732 \\
\hline
\end{tabular}

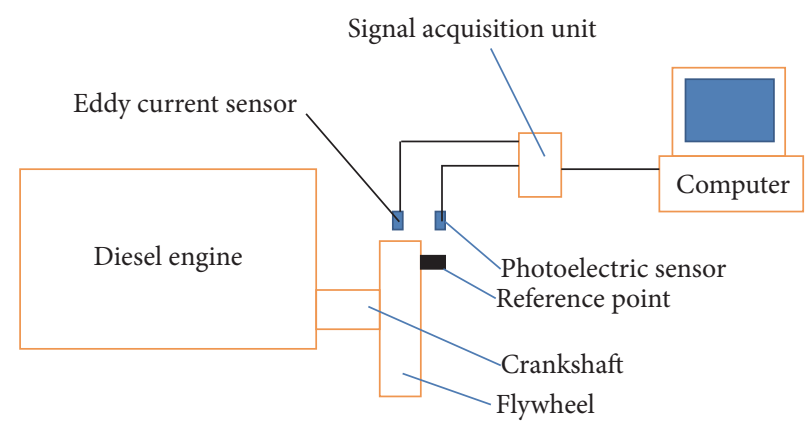

FIGURE 3: The vibration signal measuring principle.

From Figure 2 it can be seen that the harmonic wavelet denoising method can filter the high frequency noise signal. Therefore, the harmonic wavelet denoising method is used to reduce the noise signal of time domain signal firstly; then the least square method is used to fit the fundamental frequency signal of the denoised signal; therefore the signal fitting accuracy can be improved significantly.

For the comparative analysis, the least square method is, respectively, used to fit the fundamental and multiplefrequency signals before and after being denoised in Figure 2. The fitting results are shown in Table 2.

From Table 2, it can be seen that harmonic wavelet denoise method can greatly improve noise ratio of fundamental frequency signal and then improve the fitting accuracy of the least square method to the fundamental frequency and its higher order harmonic signals.

\section{Design of Vibration Monitoring System and Unbalance Adjustment Mechanism for Crankshaft System of Large Diesel Engine}

3.1. Vibration Detecting System. Flywheel is the important unit of diesel engine crankshaft system and connects with output end of crankshaft. During diesel engine running, the nonstationary and nonuniformity of crankshaft's speed can be reduced by flywheel. Based on the functional characteristics of flywheel, the rotational inertia of flywheel is larger than that of the crankshaft, so the crankshaft system can be regarded as a single face dynamic balance system.

In practice, the structure of crankshaft system is very compact, and it is not convenient to install the noncontact sensor directly to measure the vibration signal of the crankshaft. Therefore, the unbalanced vibration of the crankshaft system is investigated by directly monitoring the vibration state of the flywheel in the paper. The principle of signal measurement is shown in Figure 3.

In Figure 3, the eddy current sensor is used to measure the radial vibration displacement signals of the flywheel, and a photoelectric sensor is used to measure the reference signal. Each sensor acquisition signal is connected with the signal acquisition card through the high-performance shielding cable. Finally, the channel signals are collected through program software and analyzed in the computer. In the course of vibration signal analysis, the rising edge position of first pulse signal in the reference signal is taken as the reference zero point.

3.2. The Unbalance Adjustment Mechanism. The unbalance adjustment mechanism is designed to trial weight and correct the unbalance vector of crankshaft system. In order not to change the structure of diesel engine spindle system, the unbalance adjustment mechanism is designed as Figure 4 shows.

The mechanism is based on the flywheel at the nonoutput of the crankshaft. Four positions are drilled and tapped radially at $0^{\circ}, 90^{\circ}, 180^{\circ}$, and $270^{\circ}$ of flywheel. A long bolt is installed on each hole. Three nuts are fitted on each long bolt, of which nut 2 is used to lock the long bolt with flywheel and nut 3 to adjust and lock the radial unbalance of the long bolt. When four radial positions of nut 3 are adjusted properly, the unbalancing vector of the crankshaft system can be adjusted in $360^{\circ}$.

If equivalent unbalancing vector of crankshaft system is assumed as $\overrightarrow{U_{x}}=U_{x} \angle \alpha_{x}$ and the radial equivalent unbalance 


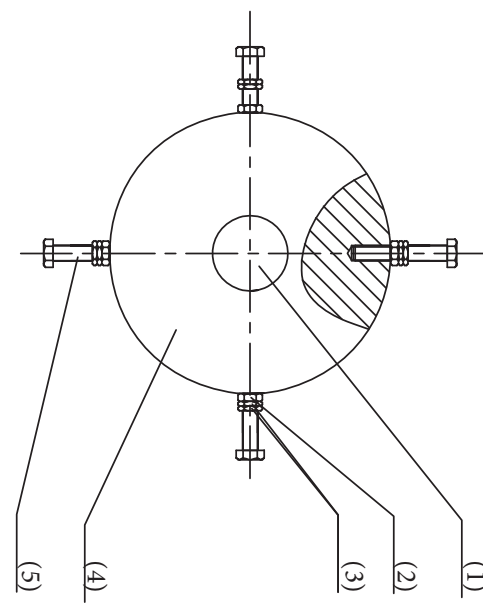

(a) The correcting mechanism

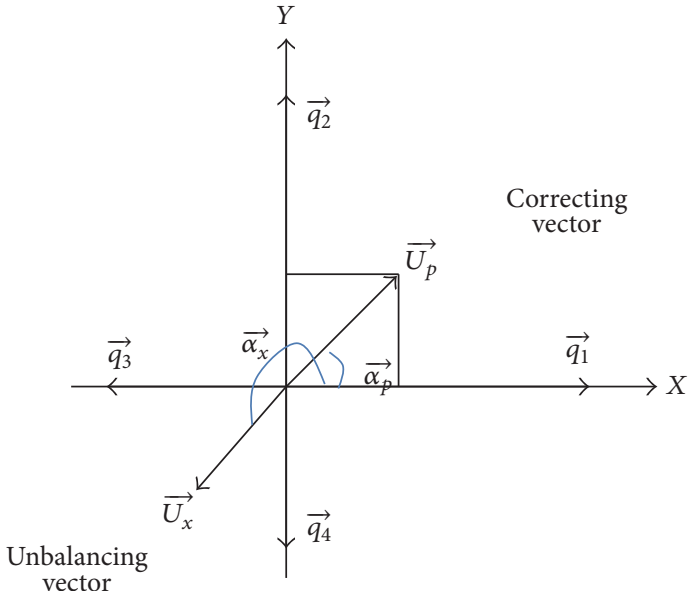

(b) The correcting principle

Figure 4: An adjustable dynamic balancing mechanism. Notes. (1) Crankshaft, (2) lock nut, (3) adjusting nut, (4) flywheel, and (5) long bolt.

vectors at $0^{\circ}, 90^{\circ}, 180^{\circ}$, and $270^{\circ}$ of flywheel are set as $\overrightarrow{q_{1}}=$ $Q_{1} \angle 0^{\circ}, \overrightarrow{q_{2}}=Q_{2} \angle 90^{\circ}, \overrightarrow{q_{3}}=Q_{3} \angle 180^{\circ}$, and $\overrightarrow{q_{4}}=Q_{4} \angle 270^{\circ}$, (15) can be got based on vector synthesis and mechanism balance principle.

$$
\overrightarrow{U_{x}}=-\left(\overrightarrow{q_{1}}+\overrightarrow{q_{2}}+\overrightarrow{q_{3}}+\overrightarrow{q_{4}}\right) .
$$

And then, the amplitude equation (16) and phase equation (17) can be got based on (15).

$$
\begin{array}{r}
U_{x}=\sqrt{\left(Q_{1}-Q_{3}\right)^{2}+\left(Q_{2}-Q_{4}\right)^{2}}=\sqrt{\Delta Q_{x}^{2}+\Delta Q_{y}^{2}} \\
\Delta Q_{x}=Q_{1}-Q_{3}, \Delta Q_{y}=Q_{2}-Q_{4}
\end{array}
$$

$\alpha_{x}$

$$
= \begin{cases}180^{\circ}+\tan ^{-1} \frac{\Delta Q_{y}}{\Delta Q_{x}}, & \alpha_{x} \in\left[0,90^{\circ}\right) \cup\left(270^{\circ}, 360^{\circ}\right] \\ \tan ^{-1} \frac{\Delta Q_{y}}{\Delta Q_{x}}, & \alpha_{x} \in\left[90^{\circ}, 270^{\circ}\right] .\end{cases}
$$

Based on (16) and (17), the required correcting vectors $\Delta Q_{x}$ and $\Delta Q_{y}$ on the $x$ - and $y$-axis of the correcting device can be calculated.

\section{Calculation of Correcting Vector Based on Influence Coefficient Method}

The influence coefficient can be defined as the unbalance vibration change of the measuring point when exerting the unit unbalance in the trial-weight face. Dynamic balancing method of influence coefficient is an experimental method in essence. The principle and process of single face influence coefficient method are described as the following.

(1) Adjust the speed of the crankshaft system to the balancing speed, measure the vibration of the flywheel and the reference signal without trial-weight, and extract the initial unbalanced vibration of the crankshaft as $\vec{V}_{0}=V_{0} \angle \phi_{0}$ with the balance speed as the fundamental frequency. Meanwhile, the initial unbalance of the crankshaft system equivalent to the flywheel is assumed as $\overrightarrow{U_{0}}=U_{0} \angle \alpha_{0}$.

(2) Adjust the equivalent unbalancing vector of the correcting mechanism as $\vec{U}=U \angle \alpha$ and the synthetic unbalancing vector of the crankshaft system and correcting vector is assumed as $\overrightarrow{U_{1}}=U_{1} \angle \alpha_{1}$. Adjust the crankshaft speed to the balance speed, and then the unbalancing vibration vector (assumed as $\vec{V}_{1}=V_{1} \angle \phi_{1}$ ) of the crankshaft system can be measured and extracted.

The vector diagrams of $\overrightarrow{V_{0}}, \overrightarrow{U_{0}}, \vec{U}, \overrightarrow{U_{1}}$, and $\vec{V}_{1}$ are shown in Figure 5.

From the geometric relation in Figure 5, the following equations can be gained.

$$
\begin{aligned}
\beta & =\phi_{0}-\phi_{1} \\
\frac{U_{1}}{U_{0}} & =\frac{V_{1}}{V_{0}} \\
U^{2} & =U_{0}^{2}+U_{1}^{2}-2 U_{0} U_{1} \cos (\beta) \\
& =U_{0}^{2}+U_{0}^{2}\left(\frac{V_{1}}{V_{0}}\right)^{2}-2 U_{0}^{2}\left(\frac{V_{1}}{V_{0}}\right) \cos (\beta) \\
U_{0} & =\frac{U_{1}}{1+\left(V_{1} / V_{0}\right)^{2}-2\left(V_{1} / V_{0}\right) \cos \beta} \\
\gamma & =\arccos \left(\frac{U^{2}+U_{1}^{2}-U_{0}^{2}}{2 U_{1}}\right) \\
\alpha_{0} & =\gamma+\beta+\alpha .
\end{aligned}
$$

Based on the definition of influence coefficient, the amplitude influence coefficient of the unbalanced vibration is shown in

$$
R=\frac{U_{0}}{V_{0}}
$$




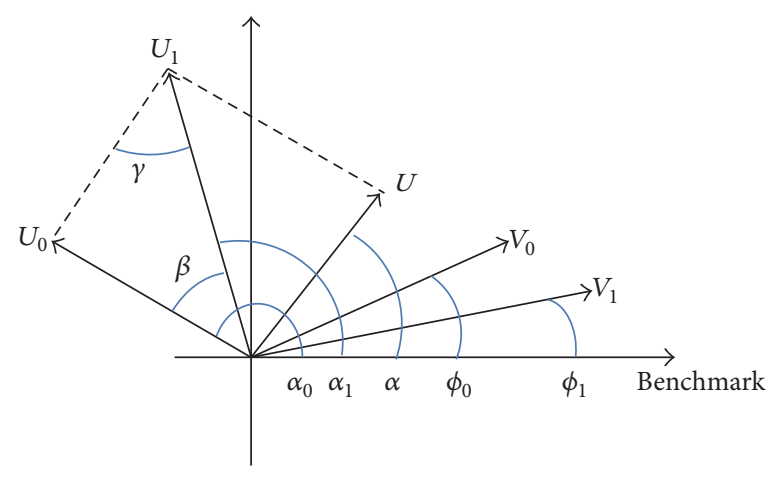

FIGURE 5: The vector relation between the exciting factors and response.

Moreover, the lag angle of the unbalanced vibration phase of measuring point lagging behind the correction vector is shown in

$$
\varphi=\alpha_{0}-\phi_{0} .
$$

The above parameters $R, \varphi$ are, respectively, stored as the influence coefficients in the system to estimate the equivalent unbalance of the crankshaft system.

(3) Set the measured unbalanced vibration signals of the crankshaft system as $\overrightarrow{V_{x}}=V_{x} \angle \phi_{x}$; then the equivalent unbalance on the flywheel of crankshaft system can be calculated by the following equations:

$$
\begin{aligned}
U_{x} & =R V_{x} \\
\alpha_{x} & =\varphi+\phi_{x} .
\end{aligned}
$$

Based on the calculated results, adjust the equivalent correcting vector of the adjustment mechanism equal to $-\overrightarrow{U_{x}}=-U_{x} \angle \alpha_{x}$, and then the unbalancing vector of crankshaft system can be corrected.

Based on the above analysis, the application steps of field dynamic balance technologies are summarized as follows for large diesel engine crankshaft system.

Step 1. The suitable correcting mechanism should be designed for trial-weight test and unbalancing adjustment. The suitable detection method should be designed to measure the vibration and reference signals of crankshaft system.

Step 2. The testing speed of crankshaft system is selected, and then the vibration and reference signals of monitoring points are acquired through series of experiments.

Step 3. The measured vibration signals are filtered by the harmonic wavelet noise reduction method.

Step 4. The least square method is used to fit the amplitude and phase of fundamental frequency signal of denoised signal, and then the actual phase of fundamental frequency signal can be calculated combining with the reference signal.
Step 5. Based on the principle and process of single face influence coefficient method, the influence coefficient between correcting mechanism and crankshaft system can be tested and calculated according to Steps 2-4.

Step 6. Adjust the synthetic unbalancing vector of correcting mechanism equal to zero, and test the actual phase and amplitude values of crankshaft system vibration, and then the correcting vector can be calculated through the influence coefficient method.

Step 7. The synthetic unbalancing vector of correcting mechanism should be adjusted equal to the correcting vector.

Step 8. The vibration experiments are carried out to test the balancing effect.

\section{Experimental Analysis}

Based on the vibration monitoring and measuring principle of Figure 3, the field measuring picture is shown in Figure 6.

Based on the above experimental principle and procedure, the correcting vector is firstly adjusted to zero in the adjustment mechanism. And set the experimental speed of diesel engine as $300 \mathrm{RPM}$, sampling frequency $1000 \mathrm{~Hz}$, and sample length 1000 points, then the vibration signals and reference signals of the measuring points are measured as Figure 7.

It can be seen from Figure 7 that the amplitude of the monitored signal is larger. Comparing with the reference signal, the fundamental frequency characteristics of the vibration signal at the measuring point are obvious, which indicates that the unbalancing vector is larger in the crankshaft system of the diesel engine. In order to improve the separating accuracy of unbalanced vibration signals, the harmonic denoise method is first used to reduce the noise signal of Figure 7. The signals are contrasted as shown in Figure 8 before and after noise reduction.

As shown in Figure 8, the signal curve after noise reduction is relatively smooth, which indicates that most of the noise signals have been filtered out. 


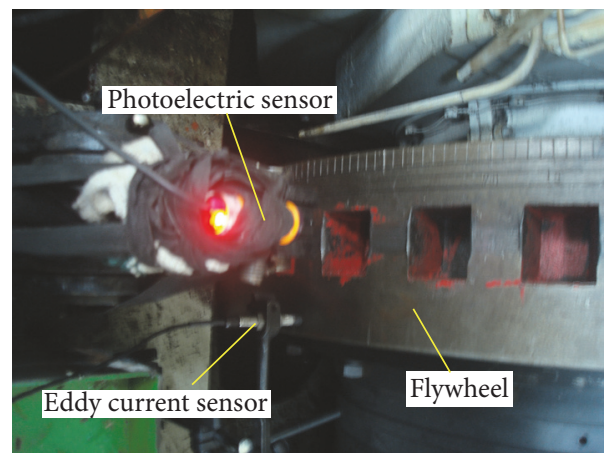

FIGURE 6: Field measuring system.

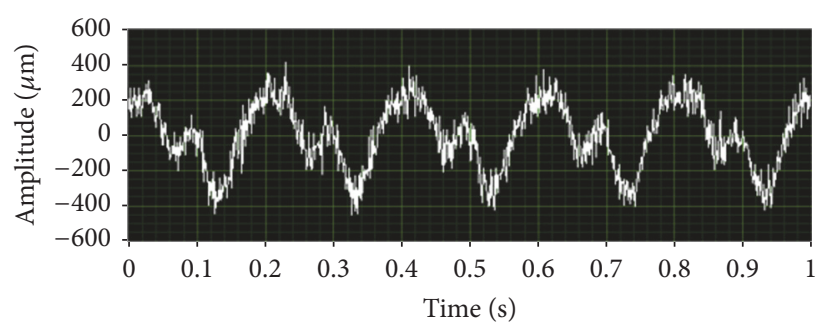

(a) The initial vibration signal of crankshaft system

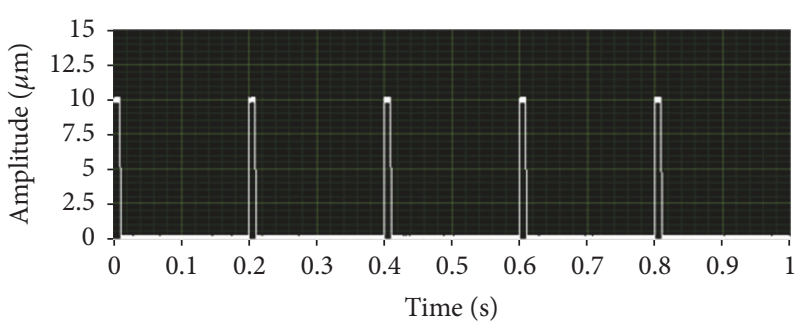

(b) The reference signal of crankshaft system

FIGURE 7: The initial vibration signal and reference signal of crankshaft system.

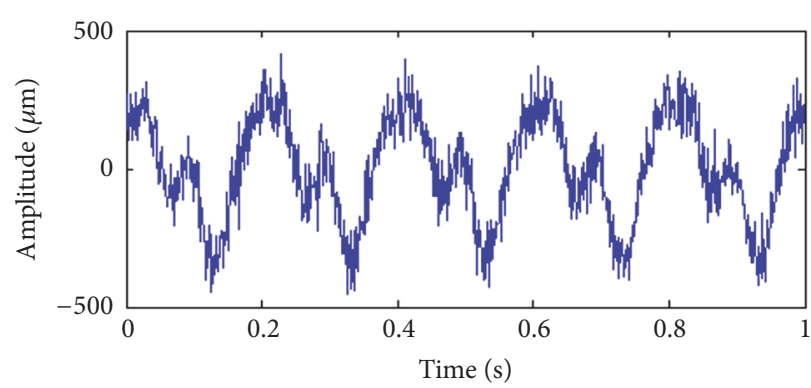

(a) The original vibration signal of crankshaft system

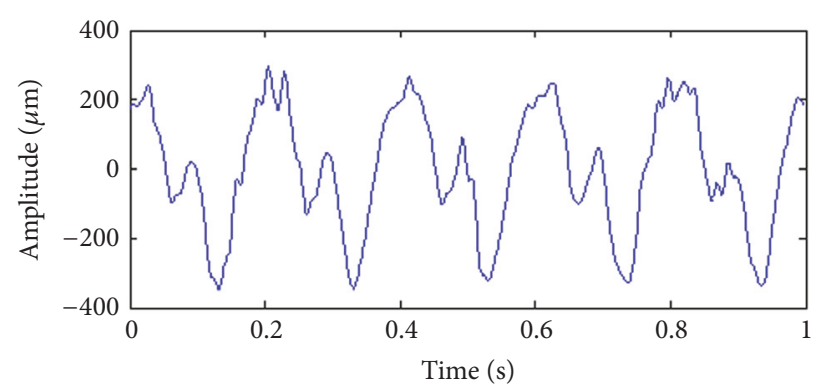

(b) The residual vibration signal after wavelet noise reduction

FIGURE 8: The filtering effect of crankshaft vibration signal based on wavelet noise reduction method.

The least square method is used to fit the fundamental frequency signal from the denoised signal, and the fitting result is shown as follows.

$$
\vec{V}_{0}=212.984 \mu \mathrm{m} \angle 57.569^{\circ}=250.963+220.624 i .
$$

In order to calculate the system influence coefficient, the unbalancing vector of trial weight is set as $\vec{U}=$ $436 \mathrm{~g} \cdot \mathrm{mm} \angle 45^{\circ}$.

Under experimental rotating speed the unbalanced vibration signals and benchmark of crankshaft system are measured as in Figure 9.

The harmonic denoise method was used to reduce the noise signal in Figure 9; then the least square method was used to fit the fundamental frequency signal to obtain the unbalanced vibration signal of the crankshaft system as the following:

$$
\vec{V}_{1}=334.152 \mu \mathrm{m} \angle 41.319^{\circ}=114.22+179.767 i .
$$

According to the influence coefficient principle, the influence coefficient of the correction plane relative to the measuring point can be calculated as

$$
\begin{aligned}
U_{0} & =650.843 \\
R & =\frac{U_{0}}{V_{0}}=\frac{650.843}{212.984}=3.0558 \\
\alpha_{0} & =85.923^{\circ} \\
\varphi & =85.923^{\circ}-57.569^{\circ}=28.354^{\circ} .
\end{aligned}
$$




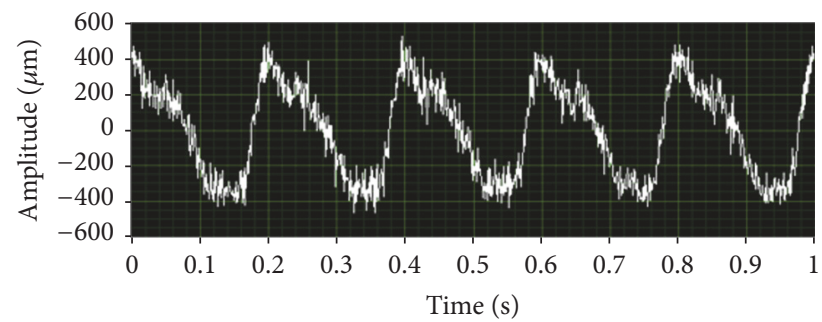

(a) The vibration signal of crankshaft system after trial weight

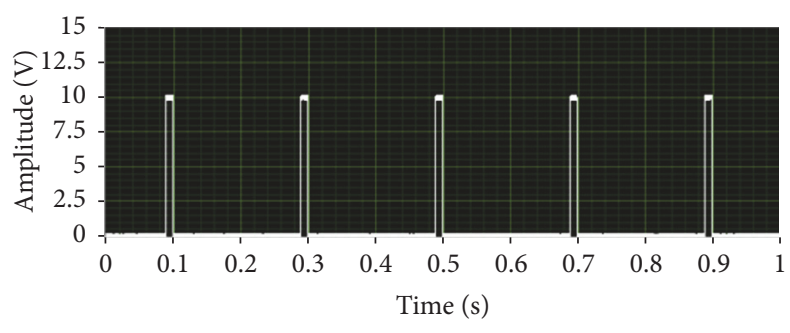

(b) The reference signal of crankshaft system

FIGURE 9: The vibration signal and reference signal of crankshaft system after trial weight.

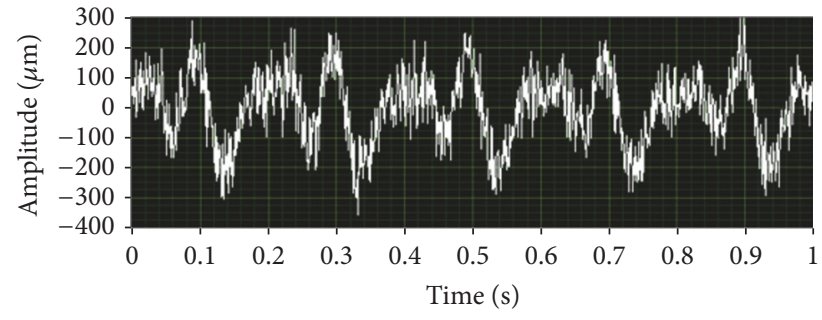

(a) The residual vibration signal of crankshaft system

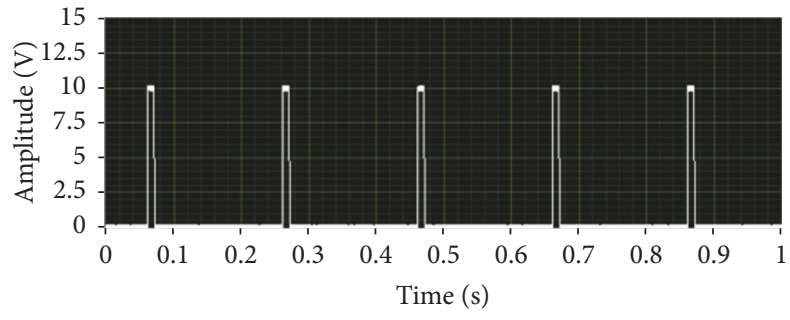

(b) The reference signal of crankshaft system

FIGURE 10: The residual vibration signal and reference signal of crankshaft system.

Taking the initial unbalanced vibration of the spindle as the correction target, the correcting vector of the correcting face is calculated as

$$
\overrightarrow{U_{p}}=650.848 \angle 265.923^{\circ} \text {. }
$$

According to the calculation result of the correcting vector, adjust the correcting vector of the adjustment mechanism, restart the diesel engine to the experimental speed, and then the detected vibration signal of the diesel engine crankshaft system is shown in Figure 10.

Compared with the signal in Figure 7, the amplitude of vibration signal in Figure 10 reduces obviously, and the noise signal is obvious. The harmonic wavelet denoise and least square method are used to get the fundamental frequency vibration signal in Figure 10, which is $35.2869 \mu \mathrm{m} \angle 29.9338^{\circ}$. The residual unbalance vibration is small, indicating that the dynamic balance is effective.

\section{Conclusions}

(1) Accurate extraction of unbalanced vibration signals of crankshaft system is the premise of dynamic balancing. Simulation analysis shows that the least square method can accurately fit the fundamental frequency and the higher order doubling frequency signal in the vibration signal, but the noise signal in vibration signal has some influence on the fitting precision of least square method.

(2) Harmonic wavelet noise reduction method has better function of "phase locking." The harmonic wavelet is used to reduce the noise signal of vibration signal, which does not affect the phase of the fundamental frequency signal. Therefore, the harmonic wavelet denoise combining with the least square method can improve the fitting accuracy of the fundamental frequency signal. Simulation analysis shows the superiority of this method in the paper.

(3) Based on the structural characteristics of crankshaft system of large diesel engine, the unbalancing vector of diesel crankshaft system can be equivalent to the flywheel. In this paper, the method of vibration detection and unbalancing adjustment mechanism is designed based on flywheel, and then the field dynamic balance can be realized in diesel crankshaft system. The experimental results show that field dynamic balancing method can effectively reduce the vibration amplitude of the flywheel.

\section{Conflicts of Interest}

The authors declare that there are no conflicts of interest regarding the publication of this paper.

\section{Acknowledgments}

This work was supported by the National Natural Science Foundation of China (no. 51605332), the Science and Technology Funds from Tianjin Municipal Education Commission (no. JWK1717), and the Innovation Team Training Plan of Tianjin Universities and Colleges (no. TD12-5043).

\section{References}

[1] F. W. Lanchester, Valve-gear of internal-combustion engines, United States Patent, US19110668055(1911).

[2] M. Ishikawa, Y. Nakamura, N. Kodama, and H. Hosoi, "Development of resin gear balance shaft system for 2AZ-FE engine," Jsae Review, vol. 23, no. 1, pp. 27-32, 2002. 
[3] W.-X. Fan, B.-C. Zhang, X.-D. Zhang, and G.-T. Yang, "Optimum of the balance mechanism for a four-cylinder in-line diesel engine," Chinese Internal Combustion Engine Engineering, vol. 28, no. 3, pp. 52-54, 2007.

[4] V. P. Solferino, Internal combustion engine with dynamic balancing system, United States Patent, US20090504699 (2009).

[5] S. C. Sajdowitz, C. D. Thorn, J. T. Bykowski, T. W. Leroy, and R. W. Albert, "Single cylinder balance system," European Patent Applications, vol. EP2977644, 2015.

[6] M. Q. Sun and Y. F. Fang, "Study on shaking force balance of internal combustion engines by total mass center displacement method," Journal of Northern Jiaotong University, vol. 24, no. 4, pp. 87-90, 2000.

[7] X. J. Sun, K. Q. Li, and X. F. Wang, "Study on an eccentric slide block balancing mechanism in a single-cylinder engine," Journal of Sound and vibration, vol. 26, no. 7, pp. 97-100, 2007.

[8] Y. Yilmaz and G. Anlas, "An investigation of the effect of counterweight configuration on main bearing load and crankshaft bending stress," Advances in Engineering Software, vol. 40, no. 2, pp. 95-104, 2009.

[9] C. Yang, Z. Hao, and G. Zheng, "Balance mechanism design of single cylinder engine based on continuous mass distribution of connecting rod," Transactions of Tianjin University, vol. 15, no. 4, pp. 255-259, 2009.

[10] C. Q. Liu and R. L. Huston, "Theoretical and practical aspects for balancing crankshafts of six-cylinder V60 degree engines," International Journal of Vehicle Noise and Vibration, vol. 7, no. 1, pp. 68-89, 2011.

[11] C.-J. Kim, Y. J. Kang, B.-H. Lee, and H.-J. Ahn, "Determination of optimal position for both support bearing and unbalance mass of balance shaft," Mechanism and Machine Theory, vol. 50, pp. 150-158, 2012.

[12] H. Karabulut, "Dynamic model of a two-cylinder four-stroke internal combustion engine and vibration treatment," International Journal of Engine Research, vol. 13, no. 6, pp. 616-627, 2012.

[13] J. Huo, H. Wu, W. Sun, J. Chen, and L. Wang, "Improved design of the transmission mechanism of the of 4-cylinder doubleacting Stirling engine," Journal of Vibroengineering, vol. 17, no. 2, pp. 643-654, 2015.

[14] D. Ipci and H. Karabulut, "Thermodynamic and dynamic modeling of a single cylinder four stroke diesel engine," Applied Mathematical Modelling, vol. 40, no. 5-6, pp. 3925-3937, 2016.

[15] R. D. Tang, Y. L. Xu, B. F. Zu, J. Liu, C. L. Hao, and D. S. Li, “Theoretical analysis of balancing of the offset crankshaft 3-cylinder engine," Chinese Internal Combustion Engine Engineering, vol. 37, no. 4, pp. 92-96, 2016.

[16] Y. Kang, Y.-P. Chang, M.-H. Tseng, P.-H. Tang, and Y.-F. Chang, "Modified approach based on influence coefficient method for balancing crank-shafts," Journal of Sound and Vibration, vol. 234, no. 2, pp. 277-296, 2000.

[17] W. G. Liu, F. Dong, and D. W. Zhao, "New concept for the balance of the second-harmonic inertia forces in an in-line, four-cylinder diesel engine," Internal Combustion Engines, vol. 18, no. 3, pp. 7-8, 2003.

[18] S. Zhang and Y. Cai, "A new double-face online dynamic balance device and its control system for high speed machine tool spindle," Journal of Vibration and Control, vol. 22, no. 4, pp. 1037-1048, 2016.

[19] Z. B. Hu, M. X. Xu, G. D. Jiang, and D. S. Zhang, "Analysis of non-stationary signal of a sudden unbalanced spindle based on wavelet noise reduction and short-time Fourier transformation," Journal of Vibration and Shock, vol. 33, no. 5, pp. 20-23, 2014.

[20] Y. Liao, G. Lang, F. Wu, and L. Qu, "An improvement to holospectrum based field balancing method by reselection of balancing object," Journal of Vibration and Acoustics, Transactions of the ASME, vol. 131, no. 3, pp. 987-1002, 2009. 


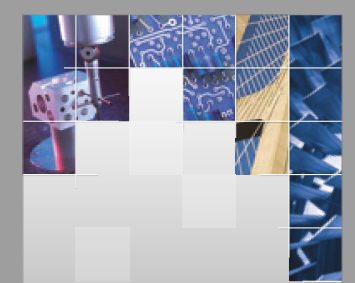

\section{Enfincering}
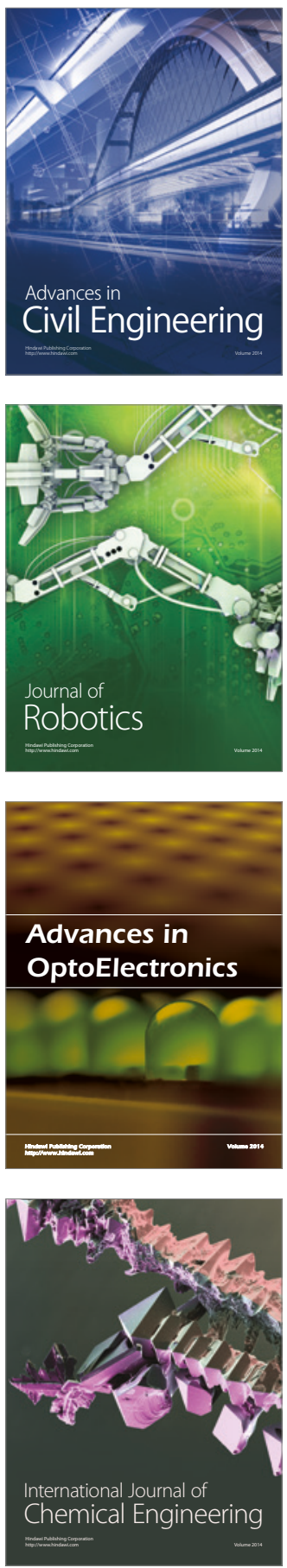

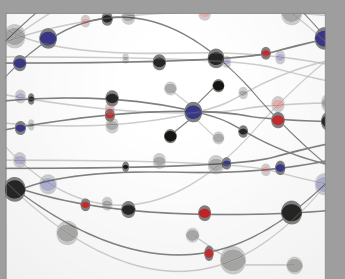

The Scientific World Journal

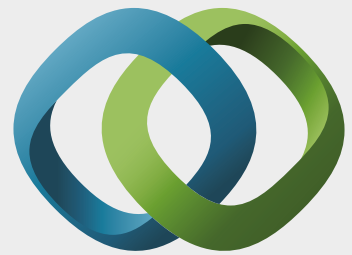

\section{Hindawi}

Submit your manuscripts at

https://www.hindawi.com
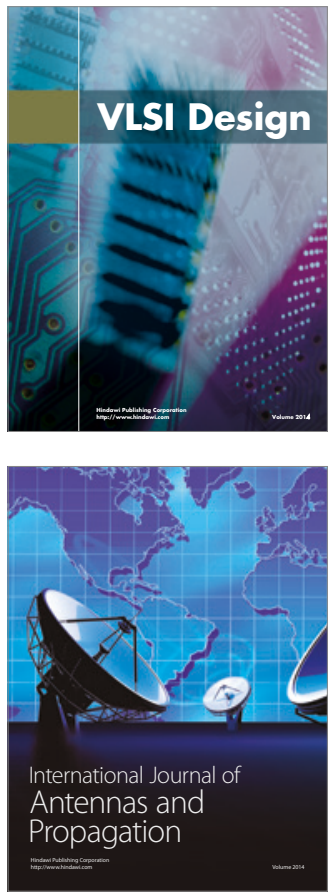

\section{Rotating}

Machinery
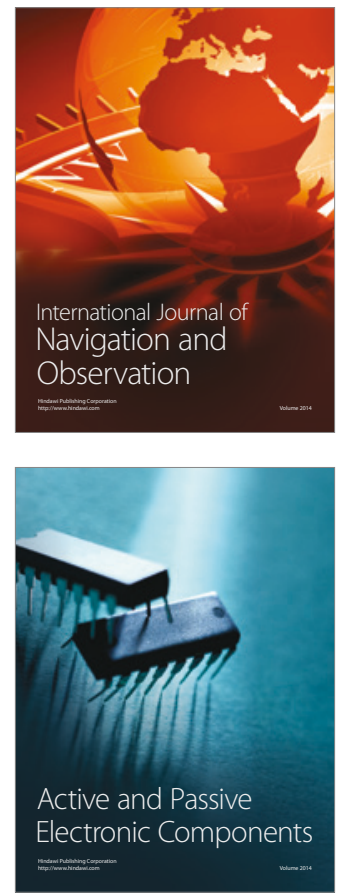
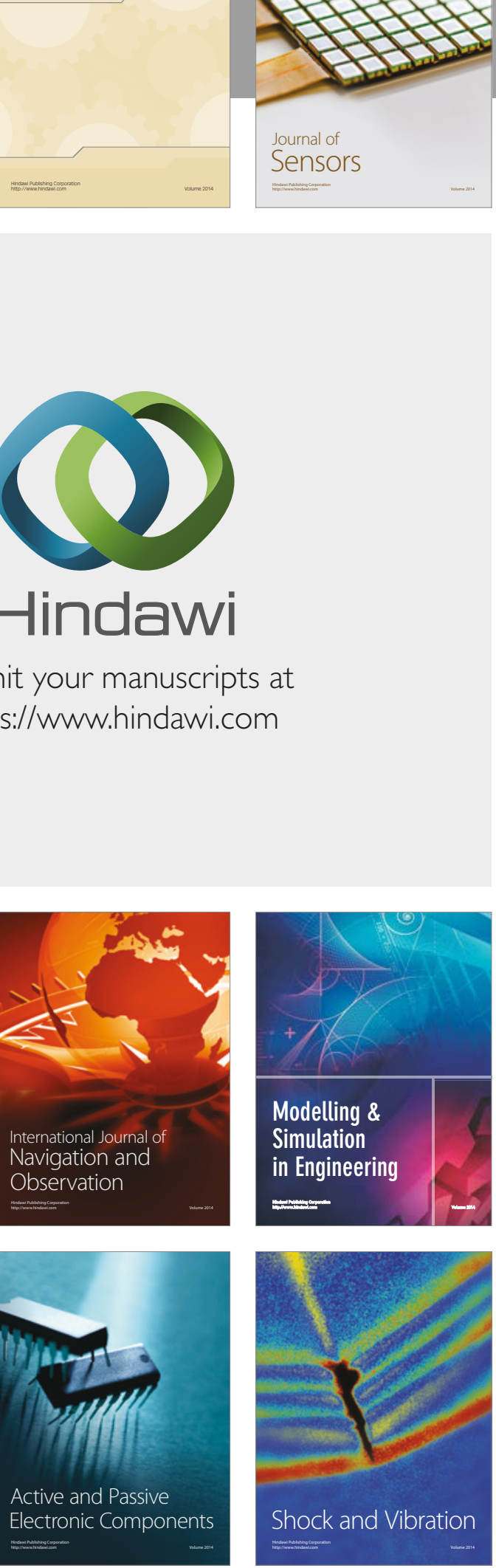
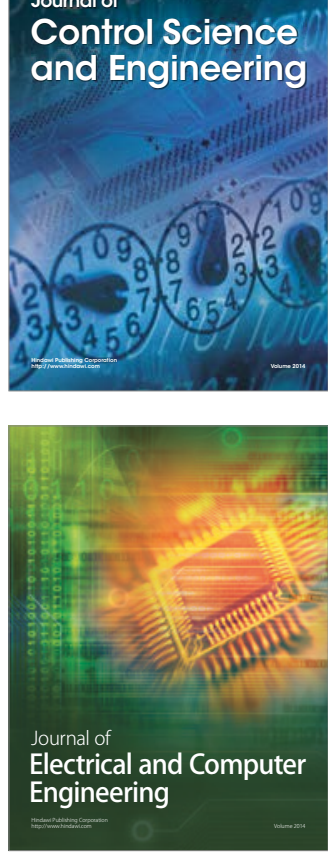

Distributed

Journal of

Control Science

and Engineering
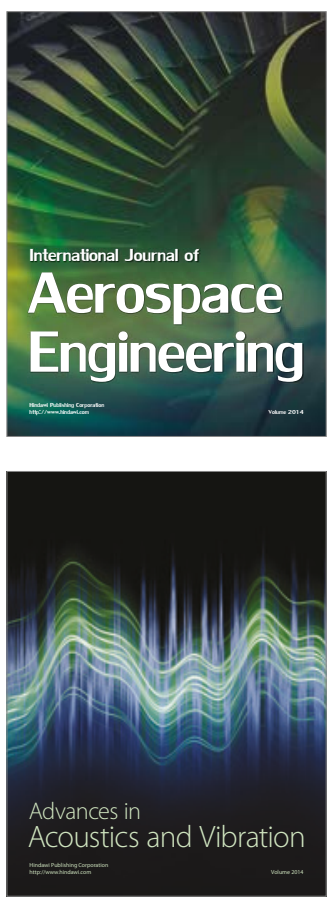

Sensor Networks 